\title{
Four Novel Loci (19q13, 6q24, 12q24, and 5q14) Influence the Microcirculation In Vivo
}

\author{
M. Kamran Ikram ${ }^{1,2,39}$, Sim Xueling ${ }^{49}$, Richard A. Jensen ${ }^{5,69}$, Mary Frances Cotch $^{79}$, Alex W. Hewitt ${ }^{89}$, \\ M. Arfan Ikram ${ }^{1}$, Jie Jin Wang ${ }^{8,9}$, Ronald Klein ${ }^{10}$, Barbara E. K. Klein ${ }^{10}$, Monique M. B. Breteler ${ }^{1}$, Ning \\ Cheung $^{8}$, Gerald Liew ${ }^{9}$, Paul Mitchell ${ }^{9}$, Andre G. Uitterlinden ${ }^{1,11,12}$, Fernando Rivadeneira ${ }^{1,11}$, Albert \\ Hofman ${ }^{1}$, Paulus T. V. M. de Jong ${ }^{13,14}$, Cornelia M. van Duijn ${ }^{1}$, Linda Kao ${ }^{15}$, Ching-Yu Cheng ${ }^{16,17}$, Albert \\ Vernon Smith ${ }^{18,19}$, Nicole L. Glazer ${ }^{5,20}$, Thomas Lumley ${ }^{5,21}$, Barbara McKnight ${ }^{5,21}$, Bruce M. \\ Psaty $5,6,20,22,23$, Fridbert Jonasson ${ }^{24,25}$, Gudny Eiriksdottir ${ }^{18}$, Thor Aspelund ${ }^{18,26}$, Global BPgen \\ Consortium $^{\alpha}$, Tamara B. Harris ${ }^{27}$, Lenore J. Launer ${ }^{27}$, Kent D. Taylor ${ }^{28}$, Xiaohui Li ${ }^{28}$, Sudha K. Iyengar ${ }^{29}$, \\ Quansheng $\mathrm{Xi}^{29}$, Theru A. Sivakumaran ${ }^{29}$, David A. Mackey ${ }^{9,30}$, Stuart MacGregor ${ }^{31}$, Nicholas G. \\ Martin $^{31}$, Terri L. Young ${ }^{32}$, Josh C. Bis ${ }^{33}$, Kerri L. Wiggins ${ }^{33}$, Susan R. Heckbert ${ }^{34,35}$, Christopher J. \\ Hammond $^{36}$, Toby Andrew ${ }^{36}$, Samantha Fahy ${ }^{36}$, John Attia ${ }^{37,38}$, Elizabeth G. Holliday ${ }^{37,38}$, Rodney J. \\ Scott $^{37,38}$, F. M. Amirul Islam ${ }^{8}$, Jerome I. Rotter ${ }^{28}$, Annie K. McAuley ${ }^{8}$, Eric Boerwinkle ${ }^{39}$, \\ E. Shyong Tai ${ }^{40,41}$, Vilmundur Gudnason ${ }^{18,19 \%}$, David S. Siscovick ${ }^{5,6,20}$, Johannes R. Vingerling ${ }^{1,2 \%}$, \\ Tien Y. Wong ${ }^{8,42,439_{*}^{*}}$
}

1 Department of Epidemiology, Erasmus Medical Center, Rotterdam, The Netherlands, 2 Department of Ophthalmology, Erasmus Medical Center, Rotterdam, The Netherlands, 3 Department of Neurology, Erasmus Medical Center, Rotterdam, The Netherlands, 4 Centre for Molecular Epidemiology, Yong Loo Lin School of Medicine, National University of Singapore, Singapore, $\mathbf{5}$ Cardiovascular Health Research Unit, University of Washington, Seattle, Washington, United States of America, 6 Department of Epidemiology, University of Washington, Seattle, Washington, United States of America, 7 Division of Epidemiology and Clinical Applications, National Eye Institute, Intramural Research Program, National Institutes of Health, Bethesda, Maryland, United States of America, 8 Centre for Eye Research Australia, University of Melbourne, Royal Victorian Eye and Ear Hospital, Melbourne, Australia, $\mathbf{9}$ Centre for Vision Research, Department of Ophthalmology and the Westmead Millennium Institute, University of Sydney, Sydney, Australia, 10 Department of Ophthalmology and Visual Science, University of Wisconsin, Madison, Wisconsin, United States of America, 11 Department of Internal Medicine, Erasmus Medical Center, Rotterdam, The Netherlands, 12 Department of Clinical Chemistry, Erasmus Medical Center, Rotterdam, The Netherlands, 13 Netherlands Institute of Neuroscience, Amsterdam, The Netherlands, 14 Department of Ophthalmology, Academic Medical Center, Amsterdam, The Netherlands, 15 Department of Epidemiology, Johns Hopkins University Bloomberg School of Public Health, Baltimore, Maryland, United States of America, 16 Department of Ophthalmology, Taipei Veterans General Hospital, Taipei, Taiwan, 17 Department of Ophthalmology, National Yang-Ming University School of Medicine, Taipei, Taiwan, 18 Icelandic Heart Association, Kopavogur, Iceland, 19 Faculty of Medicine, University of Iceland, Reykjavik, Iceland, 20 Department of Medicine, University of Washington, Seattle, Washington, United States of America, 21 Department of Biostatistics, University of Washington, Seattle, Washington, United States of America, 22 Department of Health Services, University of Washington, Seattle, Washington, United States of America, 23 Center for Health Studies, Group Health, Seattle, Washington, United States of America, 24 Department of Ophthalmology, University of Iceland, Reykjavik, Iceland, 25 Department of Ophthalmology, Landspitalinn University Hospital, Reykjavik, Iceland, 26 Department of Statistics, University of Iceland, Reykjavik, Iceland, 27 Laboratory of Epidemiology, Demography, and Biometry, National Institute on Aging, Intramural Research Program, National Institutes of Health, Bethesda, Maryland, United States of America, 28 Medical Genetics Institute, Cedars-Sinai Medical Center, Los Angeles, California, United States of America, 29 Department of Epidemiology and Biostatistics, Case Western Reserve University, Cleveland, Ohio, United States of America, 30 Lions Eye Institute, University of Western Australia, Centre for Ophthalmology and Visual Science, Perth, Australia, 31 Genetics and Population Health, Queensland Institute of Medical Research, Brisbane, Australia, 32 Center for Human Genetics, Duke University Medical Center, Durham, North Carolina, United States of America, 33 Cardiovascular Health Research Unit, Department of Medicine, University of Washington, Seattle, Washington, United States of America, 34 Cardiovascular Health Research Unit, Department of Epidemiology, University of Washington, Seattle, Washington, United States of America, 35 Center for Health Studies, Group Health, Seattle, Washington, United States of America, 36 Department of Twin Research and Genetic Epidemiology, King's College London School of Medicine, St Thomas' Hospital, London, United Kingdom, $\mathbf{3 7}$ School of Biomedical Sciences, University of Newcastle, Callaghan, Australia, $\mathbf{3 8}$ Hunter Medical Research Institute, Newcastle, Australia, $\mathbf{3 9}$ Human Genetics Center and Institute of Molecular Medicine, University of Texas Health Science Center at Houston, Houston, Texas, United States of America, $\mathbf{4 0}$ Department of Epidemiology and Public Health, Yong Loo Lin School of Medicine, National University of Singapore, Singapore, 41 Department of Medicine, Yong Loo Lin School of Medicine, National University of Singapore, Singapore, 42 Singapore National Eye Centre and Singapore Eye Research Institute, Singapore, 43 Department of Ophthalmology, Yong Loo Lin School of Medicine, National University of Singapore, Singapore 


\section{Abstract}

There is increasing evidence that the microcirculation plays an important role in the pathogenesis of cardiovascular diseases. Changes in retinal vascular caliber reflect early microvascular disease and predict incident cardiovascular events. We performed a genome-wide association study to identify genetic variants associated with retinal vascular caliber. We analyzed data from four population-based discovery cohorts with 15,358 unrelated Caucasian individuals, who are members of the Cohort for Heart and Aging Research in Genomic Epidemiology (CHARGE) consortium, and replicated findings in four independent Caucasian cohorts $(n=6,652)$. All participants had retinal photography and retinal arteriolar and venular caliber measured from computer software. In the discovery cohorts, 179 single nucleotide polymorphisms (SNP) spread across five loci were significantly associated $\left(p<5.0 \times 10^{-8}\right)$ with retinal venular caliber, but none showed association with arteriolar caliber. Collectively, these five loci explain $1.0 \%-3.2 \%$ of the variation in retinal venular caliber. Four out of these five loci were confirmed in independent replication samples. In the combined analyses, the top SNPs at each locus were: rs 2287921 (19q13; $\mathrm{p}=1.61 \times 10^{-25}$, within the RASIP1 locus), rs225717 (6q24; $\mathrm{p}=1.25 \times 10^{-16}$, adjacent to the VTA1 and NMBR loci), rs10774625 (12q24; $\mathrm{p}=2.15 \times 10^{-13}$, in the region of ATXN2,SH2B3 and PTPN11 loci), and rs17421627 (5q14; $\mathrm{p}=7.32 \times 10^{-16}$, adjacent to the MEF2C locus). In two independent samples, locus $12 q 24$ was also associated with coronary heart disease and hypertension. Our population-based genome-wide association study demonstrates four novel loci associated with retinal venular caliber, an endophenotype of the microcirculation associated with clinical cardiovascular disease. These data provide further insights into the contribution and biological mechanisms of microcirculatory changes that underlie cardiovascular disease.

Citation: Ikram MK, Xueling S, Jensen RA, Cotch MF, Hewitt AW, et al. (2010) Four Novel Loci (19q13, 6q24, 12q24, and 5q14) Influence the Microcirculation In Vivo. PLoS Genet 6(10): e1001184. doi:10.1371/journal.pgen.1001184

Editor: Mark I. McCarthy, University of Oxford, United Kingdom

Received April 26, 2010; Accepted September 28, 2010; Published October 28, 2010

This is an open-access article distributed under the terms of the Creative Commons Public Domain declaration which stipulates that, once placed in the public domain, this work may be freely reproduced, distributed, transmitted, modified, built upon, or otherwise used by anyone for any lawful purpose.

Funding: Age Gene/Environment Susceptibility - Reykjavik Study: Age, Gene/Environment Susceptibility - Reykjavik Study received funding from the Intramural Research Program of the National Institute on Aging (Z01AG007380, NIH contract N01-AG-12100) and the National Eye Institute (Z01EY000401) at the National Institutes of Health, Hjartavernd (the Icelandic Heart Association), and the Althingi (the Icelandic Parliament). Atherosclerosis Risk in Communities Study: The Atherosclerosis Risk in Communities is supported by the National Heart, Lung, and Blood Institute contracts N01-HC-55015, N01-HC-55016, N01-HC-55018, N01HC-55019, N01-HC-55020, N01-HC-55021, N01-HC-55022, and R01HL087641; National Human Genome Research Institute award U01HG004402; NIH Intramural Research award Z01EY000426 from the National Eye Institute; and National Institutes of Health contract HHSN268200625226C. Infrastructure was partly supported by Grant Number UL1RR025005, a component of the National Institutes of Health and NIH Roadmap for Medical Research. Cardiovascular Health Study: The CHS research reported in this article was supported by contract numbers N01-HC-85079 through N01-HC-85086, N01-HC-35129, N01 HC-15103, N01 HC-55222, N01-HC-75150, N01-HC-45133, grant numbers U01 HL080295 and R01 HL087652 from the National Heart, Lung, and Blood Institute, with additional contribution from the National Institute of Neurological Disorders and Stroke. DNA handling and genotyping was supported in part by National Center for Research Resources grant M01RR00069 to the Cedars-Sinai General Clinical Research Center Genotyping core and National Institute of Diabetes and Digestive and Kidney Diseases grant DK063491 to the Southern California Diabetes Endocrinology Research Center. Additional support included the National Heart, Lung, and Blood Institute Training Grant T32HL007902 (RAJ). Rotterdam Study: The GWA database of the Rotterdam Study was funded through the Netherlands Organization of Scientific Research NWO (no. 175.010.2005.011). This study was further supported by the Netherlands Genomics Initiative (NGI)/Netherlands Organisation for Scientific Research (NWO) project nr. 050-060-810. We thank Dr. Michael Moorhouse, Pascal Arp, and Mila Jhamai for their help in creating the database. The Rotterdam Study is supported by the Erasmus Medical Center and Erasmus University, Rotterdam; the Netherlands Organization for scientific research (NWO); the Netherlands Organization for the Health Research and Development (ZonMw); The Research Institute for Diseases in the Elderly (RIDE); the Ministry of Education, Culture, and Science; the Ministry for Health, Welfare, and Sports; The European commission (DG XII); and the Municipality of Rotterdam. The ophthalmic part of the Rotterdam Study was supported by Lijf en Leven, Krimpen a/d Lek; MD Fonds, Utrecht. Oogfonds Nederland, Utrecht; Stichting Nederlands Oogheelkundig Onderzoek, Nijmegen/Rotterdam; Swart van Essen, Rotterdam; Netherlands Organisation for Scientific Research (NWO); Bevordering van Volkskracht, Rotterdam; Blindenhulp, The Hague; Rotterdamse Vereniging Blindenbelangen, Rotterdam; OOG, The Hague; Algemene Nederlandse Vereniging ter Voorkoming van Blindheid, Doorn; Blinden-Penning, Amsterdam; Blindenhulp, Gravenzande; Henkes Stichting, Rotterdam; Topcon Europe BV, Capelle aan de IJssel; Medical Workshop BV, Groningen; all in the Netherlands; Heidelberg Engineering, Dossenheim, Germany. Australian Twins Study: The Australian Twin Registry is supported by an Australian National Health and Medical Research Council (NHMRC) Enabling Grant (2004-2009). We also thank the following organisations for their financial support: Clifford Craig Medical Research Trust, Ophthalmic Research Institute of Australia, Glaucoma Australia, American Health Assistance Foundation, Peggy and Leslie Cranbourne Foundation, Foundation for Children, NHMRC project grant (2005-2007), Jack Brockhoff Foundation, NEI Project Grant (2007-2010).

Competing Interests: The authors have declared that no competing interests exist.

*E-mail: ophwty@nus.edu.sg

9 These authors contributed equally to this work.

- These authors also contributed equally to this work.

a Membership of the Global BPgen Consortium is provided in the Acknowledgments.

\section{Introduction}

Although both macrovascular and microvascular pathology are associated with cardiovascular disease, including coronary artery disease and stroke [1,2], most studies on the genetic determinants of cardiovascular disease have primarily focused on macrovascular disease traits, and genetic analyses of microvascular disease phenotypes are rare $[2,3]$. This paucity of data is due to difficulties in non-invasively assessing the microcirculation. However, retinal arterioles and venules, which range between 50 to $300 \mu \mathrm{m}$ in diameter, can be directly imaged, and provide an ideal opportunity to study the microcirculation in vivo [4].

Quantitative measurement of retinal blood vessel caliber from photographs allows a non-invasive direct assessment of the human microcirculation [4]. Studies using this technique have shown that changes in retinal vascular caliber (e.g., narrower arteriolar and wider venular caliber) are associated with a range of cardiovascular diseases and their risk factors [5,6], including hypertension [7], diabetes mellitus [8,9], stroke [10], coronary heart disease [11], and cerebral small vessel disease $[12,13]$. Retinal vascular caliber is also 


\section{Author Summary}

The microcirculation plays an important role in the development of cardiovascular diseases. Retinal vascular caliber changes reflect early microvascular disease and predict incident cardiovascular events. In order to identify genetic variants associated with retinal vascular caliber, we performed a genome-wide association study and analyzed data from four population-based discovery cohorts with 15,358 unrelated Caucasian individuals, who are members of the Cohort for Heart and Aging Research in Genomic Epidemiology (CHARGE) consortium, and replicated findings in four independent Caucasian cohorts $(n=6,652)$. We found evidence for association of four loci with retinal venular caliber: on chromosomes $19 q 13$ within the RASIP1 locus, $6 \mathrm{q} 24$ adjacent to the VTA1 and NMBR loci, 12q24 in the region of $A T X N 2, S H 2 B 3$ and PTPN11 loci, and $5 q 14$ adjacent to the MEF2C locus. In two independent samples, locus 12q24 was also associated with coronary heart disease and hypertension. In the present study, we demonstrate that four novel loci were associated with retinal venular caliber, an endophenotype of the microcirculation associated with clinical cardiovascular disease. Our findings will help focus research on novel genes and pathways involving the microcirculation and its role in the development of cardiovascular disease. specific genetic factors underlying retinal vascular caliber could therefore demonstrate novel insights into the mechanisms that contribute to the microvascular pathways of cardiovascular and eye diseases. To identify the underlying genetic determinants of retinal arteriolar and venular caliber, we meta-analyzed results of genome-wide association studies (GWAS) of 15,358 white participants from four large, prospective population-based cohorts included in the Cohorts for Heart and Aging Research in Genomic Epidemiology (CHARGE) consortium [21]: the Age Gene/Environment Susceptibility - Reykjavik Study (AGES) [22], the Atherosclerosis Risk in Communities Study (ARIC) [23], the Cardiovascular Health Study (CHS) [24] and the Rotterdam Study [25]. We replicated our findings in four independent cohorts of Caucasian ethnicity [the Australian Twins Study [26], the UK Twins Study [27], the Beaver Dam Eye Study (BDES) [11], and the Blue Mountains Eye Study (BMES)] [11]. Finally, in order to examine the association between the replicated hits and cardiovascular diseases, we used data on coronary artery disease from the Wellcome Trust Case Control Consortium (WTCCG) [3], on stroke and myocardial infarction from the Heart and Vascular Health $(\mathrm{HVH})$ Study [28,29], on hypertension from the Global Blood Pressure Genetics (Global BPgen) Consortium [30], and on diabetes mellitus from the Diabetes Genetics Replication and Meta-analysis + (DIAGRAM+) Consortium [31].

\section{Results}

\section{Study samples}

The total study sample for the discovery analyses was 15,358 and for the replication analyses 6,652. Characteristics of both the discovery and replication samples are presented in Table 1. and age-related macular degeneration [14-16].

Recent studies suggest that genetic factors may play a role in influencing retinal vascular caliber [17-20], so understanding

Table 1. Baseline characteristics of both the discovery and replication cohorts.

\begin{tabular}{|c|c|c|c|c|c|c|c|c|}
\hline & \multicolumn{4}{|c|}{ Discovery cohorts } & \multicolumn{4}{|c|}{ Replication cohorts } \\
\hline & AGES & $A R I C$ & $\mathrm{CHS}$ & $R S$ & $\begin{array}{l}\text { Australian } \\
\text { Twins }\end{array}$ & UK Twins & $B D E S$ & BMES \\
\hline Original cohort & 5,764 & 15,792 & 5,888 & 7,983 & 2,235 & 8,810 & 2,579 & 3,508 \\
\hline Non-Hispanic whites in original cohort & & 11,478 & 4,925 & 7,983 & 2,190 & 8,810 & 2,579 & 3,487 \\
\hline Total number included in analyses & 2,949 & 6,317 & 1,272 & 4,820 & 1,709 & 1,132 & 2,522 & 1,310 \\
\hline Mean age (years) (SD) [range] & $\begin{array}{l}76.2(5.4) \\
{[66-94]}\end{array}$ & $\begin{array}{l}60.3(5.6) \\
{[50-72]}\end{array}$ & $\begin{array}{l}78.4(4.1) \\
{[72-95]}\end{array}$ & $\begin{array}{l}68.0(8.2) \\
{[55-99]}\end{array}$ & $\begin{array}{l}22.5(12.4) \\
{[5-90]}\end{array}$ & $\begin{array}{l}58.1(10.1) \\
{[16-81]}\end{array}$ & $\begin{array}{l}60.6(10.8) \\
{[43-86]}\end{array}$ & $\begin{array}{l}66.0(8.6) \\
{[49-93]}\end{array}$ \\
\hline Proportion female (\%) & 57.5 & 52.9 & 62.9 & 59.0 & 57.0 & 97.7 & 55.8 & 58.4 \\
\hline Mean CRAE $(\mu \mathrm{m})(\mathrm{SD})$ [range] & $\begin{array}{l}139.7(13.4) \\
{[74.0-221.4]}\end{array}$ & $\begin{array}{l}136.1(14.3) \\
{[72.6-203.8]}\end{array}$ & $\begin{array}{l}140.4(15.7) \\
{[77.6-197.4]}\end{array}$ & $\begin{array}{l}150.0(14.4) \\
{[98.5-235.4]}\end{array}$ & $\begin{array}{l}164.2(13.6) \\
{[83.6-205.2]}\end{array}$ & $\begin{array}{l}163.8(18.1) \\
{[91.0-219.6]}\end{array}$ & $\begin{array}{l}149.5(13.7) \\
{[100.3-196.6]}\end{array}$ & $\begin{array}{l}160.0(20.2) \\
{[93.4-213.4]}\end{array}$ \\
\hline Mean CRVE $(\mu \mathrm{m})(\mathrm{SD})$ [range] & $\begin{array}{l}202.0(19.5) \\
{[123.8-273.0]}\end{array}$ & $\begin{array}{l}199.4(19.2) \\
{[129.3-304.1]}\end{array}$ & $\begin{array}{l}196.5(19.2) \\
{[142.5-271.7]}\end{array}$ & $\begin{array}{l}226.0(20.1) \\
{[162.5-324.3]}\end{array}$ & $\begin{array}{l}248.0(19.0) \\
{[130.5-325.7]}\end{array}$ & $\begin{array}{l}253.0(28.6) \\
{[147.0-338.0]}\end{array}$ & $\begin{array}{l}230.3(21.7) \\
{[165.9-335.1]}\end{array}$ & $\begin{array}{l}238.4(24.0) \\
{[167.6-331.1]}\end{array}$ \\
\hline $\begin{array}{l}\text { Systolic blood pressure }(\mathrm{mm} \mathrm{Hg})(\mathrm{SD}) \\
\text { [range] }\end{array}$ & $\begin{array}{l}142.5(20.2) \\
{[92-253]}\end{array}$ & $\begin{array}{l}122.9(18.1) \\
{[75-226]}\end{array}$ & $\begin{array}{l}134.4(20.4) \\
{[82-241]}\end{array}$ & $\begin{array}{l}138.5(22.1) \\
{[74-250]}\end{array}$ & $\mathrm{N} / \mathrm{A}$ & $\begin{array}{l}130.5(19.7) \\
{[85-210]}\end{array}$ & $\begin{array}{l}130.5(20.0) \\
{[71-248]}\end{array}$ & $\begin{array}{l}146.0(20.5) \\
{[95-240]}\end{array}$ \\
\hline $\begin{array}{l}\text { Diastolic blood pressure }(\mathrm{mm} \mathrm{Hg})(\mathrm{SD}) \\
\text { [range] }\end{array}$ & $\begin{array}{l}74.1(20.2) \\
{[92-253]}\end{array}$ & $\begin{array}{l}70.8(10.0) \\
{[32-114]}\end{array}$ & $\begin{array}{l}67.9(10.8) \\
{[15-110]}\end{array}$ & $\begin{array}{l}73.7(11.4) \\
{[24-139]}\end{array}$ & $\mathrm{N} / \mathrm{A}$ & $\begin{array}{l}79.5(11.9) \\
{[50-124]}\end{array}$ & $\begin{array}{l}77.4(10.8) \\
{[44-123]}\end{array}$ & $\begin{array}{l}83.6(9.8) \\
{[50-125]}\end{array}$ \\
\hline Hypertension (\%) & 80.6 & 35.3 & 48.7 & 42.3 & 3.2 & 41.7 & 35.1 & 46.1 \\
\hline Diabetes mellitus (\%) & 11.4 & 12.4 & 12.2 & 10.0 & 1.0 & 1.5 & 10.3 & 7.9 \\
\hline Current smokers (\%) & 12.5 & 17.3 & 6.2 & 23.6 & 11.0 & 13.8 & 21.6 & 12.4 \\
\hline Body mass index $\left(\mathrm{kg} / \mathrm{m}^{2}\right)(\mathrm{SD})$ [range] & $\begin{array}{l}27.1(4.4) \\
{[14.8-48.5]}\end{array}$ & $\begin{array}{l}28.0(5.2) \\
{[14.2-59.1]}\end{array}$ & $\begin{array}{l}26.8(4.3) \\
{[15.6-46.7]}\end{array}$ & $\begin{array}{l}26.3(3.7) \\
{[14.2-50.7]}\end{array}$ & $\mathrm{N} / \mathrm{A}$ & $\begin{array}{l}25.6(4.3) \\
{[15.0-48.2]}\end{array}$ & $\begin{array}{l}28.3(5.2) \\
{[15-55]}\end{array}$ & $\begin{array}{l}26.3(4.4) \\
15.2-49.2\end{array}$ \\
\hline
\end{tabular}

AGES: Age Gene/Environment Susceptibility - Reykjavik Study; ARIC: Atherosclerosis Risk in Communities Study; CHS: Cardiovascular Health Study; RS: Rotterdam Study; BDES: Beaver Dam Eye Study; BMES: Blue Mountains Eye Study; CRAE: central retinal arteriolar equivalent; CRVE: central retinal venular equivalent; SD: standard deviation; N/A Not available.

doi:10.1371/journal.pgen.1001184.t001 


\section{Meta-analysis of CHARGE cohort results}

A total of 179 single nucleotide polymorphisms (SNPs) at five loci surpassed our preset threshold $\left(\mathrm{p}<5.0 \times 10^{-8}\right)$ for genome-wide significance for retinal venular caliber. Collectively, these five independent loci explain $1.0-3.2 \%$ of the variation in retinal venular caliber within our discovery cohorts. The QQ-plots (Figure S1A) show departure from the line of identity at approximately $\mathrm{p}<1.0 \times 10^{-3}$. Figure $1 \mathrm{~A}$ displays the minus log-transformed $\mathrm{p}$ values for the individual SNPs against their genomic position. Table 2 summarizes both the meta-analyzed results and results from each discovery cohort individually for the most significant SNPs at each locus that were associated with retinal venular caliber.

No genome-wide significant locus was identified for retinal arteriolar caliber and only one SNP was associated with retinal arteriolar caliber at a significance threshold between $5.0 \times 10^{-8}$ and $1.0 \times 10^{-6}$. The QQ-plot (Figure S1B) showed a departure from the line of identity at approximately $\mathrm{p}<1.0 \times 10^{-4}$. Figure $1 \mathrm{~B}$ displays the minus log-transformed $\mathrm{p}$-values for the individual SNPs against their genomic position. The most significant signal was on chromosome 13q12 (rs2281827, per minor allele (T) copy $1.0 \mu \mathrm{m}$ (SE: 0.21) increase in arteriolar caliber; minor allele frequency $(\mathrm{MAF})$ : $0.23 ; \mathrm{p}=3.53 \times 10^{-7}$ ). This signal on chromosome 13 q12 was located in FLT1, also known as vascular endothelial growth factor receptor.

\section{Replication in independent cohorts}

Table 3 shows the results within each replication cohort for the five loci that were genome-wide significant in the discovery phase. Minor allele frequencies in the replication cohorts were very similar to that in the discovery cohorts. Four out of the five loci showed consistent effects in the combined analyses of the replication cohorts at a Bonferroni-corrected significance threshold of $\mathrm{p}<0.01(0.05 / 5$, as five loci were tested in the replication phase), the exception was rs7824557 (8p23). The combined analyses of the discovery and replication cohorts yielded an overall $\mathrm{p}$-value of $1.61 \times 10^{-25}$ for $\mathrm{rs} 2287921$ (19q13). The corresponding values for the other loci were $p=1.25 \times 10^{-16}$ for $\mathrm{rs} 225717$ (6q24), p $=2.15 \times 10^{-13}$ for $\mathrm{rs} 10774625(12 \mathrm{q} 24)$ and $\mathrm{p}=7.32 \times 10^{-16}$ for $\mathrm{rs} 17421627$ (5q14). Finally, for rs7824557 (8p23) the overall $\mathrm{p}$-value did not reach genome-wide significance $\left(\mathrm{p}=3.80 \times 10^{-7}\right)$.

The regional association plots for these four loci are presented in Figure 2A-2D. After additional adjustments for hypertension and diabetes mellitus, the associations between the four replicated loci and retinal venular caliber remained the same (Table S1).

\section{Associations with cardiovascular diseases}

Table 4 presents the results with clinical cardiovascular diseases for the four loci that were successfully replicated in the replication cohorts. These association results provided evidence for $12 q 24$ as a risk locus for coronary artery disease and hypertension. The allelic odds ratios of rs 10774625 were 1.13 (95\% confidence interval (CI): $1.03-1.24 ; \mathrm{p}=0.008)$ for coronary artery disease and $1.06(95 \%$ CI: $1.01-1.12 ; \mathrm{p}=0.019)$ for hypertension. As we found the most convincing evidence for rs10774625 to be associated with coronary artery disease, we examined the association with coronary artery disease for all 10 SNPs on locus $12 q 24$ that were genome-wide significant in the current analysis with retinal venular caliber. Figure 3 shows a plot in which the p-values for these 10 SNPs from the current analysis are combined with those for coronary artery disease from WTCCC. We found that all 10 SNPs were significantly associated with coronary artery disease at a nominal p-value of 0.05 suggesting a strong overlap between the association signals of retinal venular caliber and coronary artery disease.

\section{Discussion}

In this meta-analysis of GWAS data from four populations on retinal microcirculation and subsequent replication in four independent cohorts, we identified four novel loci on chromosomes 19q13, 6q24, 12q24 and 5q14 that were consistently associated with retinal venular caliber in persons of Caucasian descent at genome-wide significance of $<5.0 \times 10^{-8}$. The most significant SNPs at each of the four loci were associated with an approximate $2.0 \mu \mathrm{m}$ change in retinal venular caliber for each copy of the minor allele. Locus 12q24 was also associated with coronary heart disease and hypertension. We did not find any loci that reached genome-wide significance for retinal arteriolar caliber, and only one SNP reached highly suggestive levels.

Our study is the first large study to evaluate common genetic variants of the microcirculation, increasingly thought to play a substantial role in the pathogenesis and development of clinical cardiovascular diseases, including coronary heart disease and stroke. The retinal vasculature provides a non-invasive direct view of the human microcirculation. Retinal venular caliber has been shown to predict a range of subclinical [5] and clinical cardiovascular disease [6]. In a recent meta-analysis, wider retinal venules were associated with a hazard ratio of 1.16 (95\% CI: $1.06-$ 1.26) for coronary artery disease in women while controlling for other known cardiovascular risk factors [11]. Furthermore, wider venular caliber predicted risk of stroke and is associated with progression of cerebral white matter lesions $[10,12]$. Both systemic and environmental factors likely induce variation in retinal venular caliber along with individual genetic differences [5,6,17-20]. Wider retinal venular caliber has been hypothesized to reflect the effects of hypoxia [32], and an increased nitric oxide production and release of cytokines resulting from activated endothelial cells
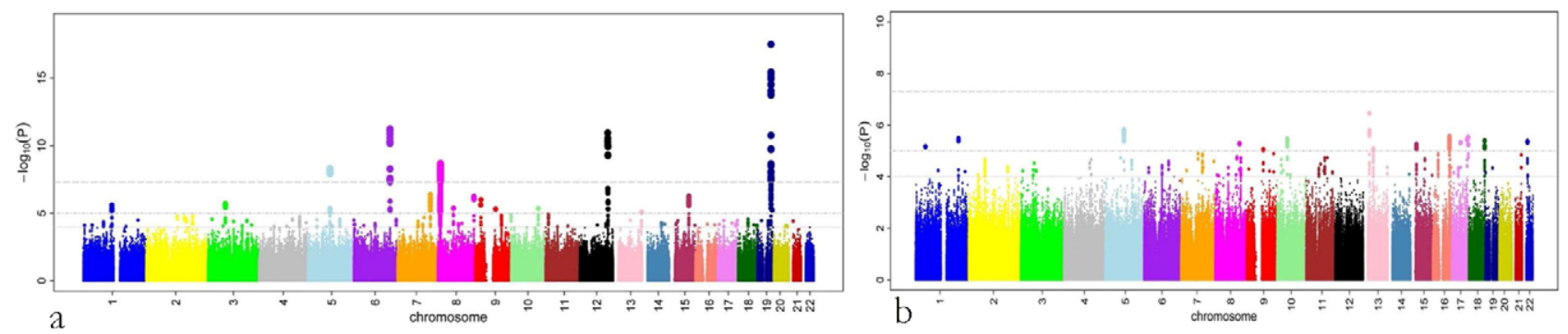

Figure 1. P-values (minus log-transformed) are shown in a signal intensity (Manhattan) plot relative to their genomic position. For (a) retinal venular caliber and (b) retinal arteriolar caliber.

doi:10.1371/journal.pgen.1001184.g001 


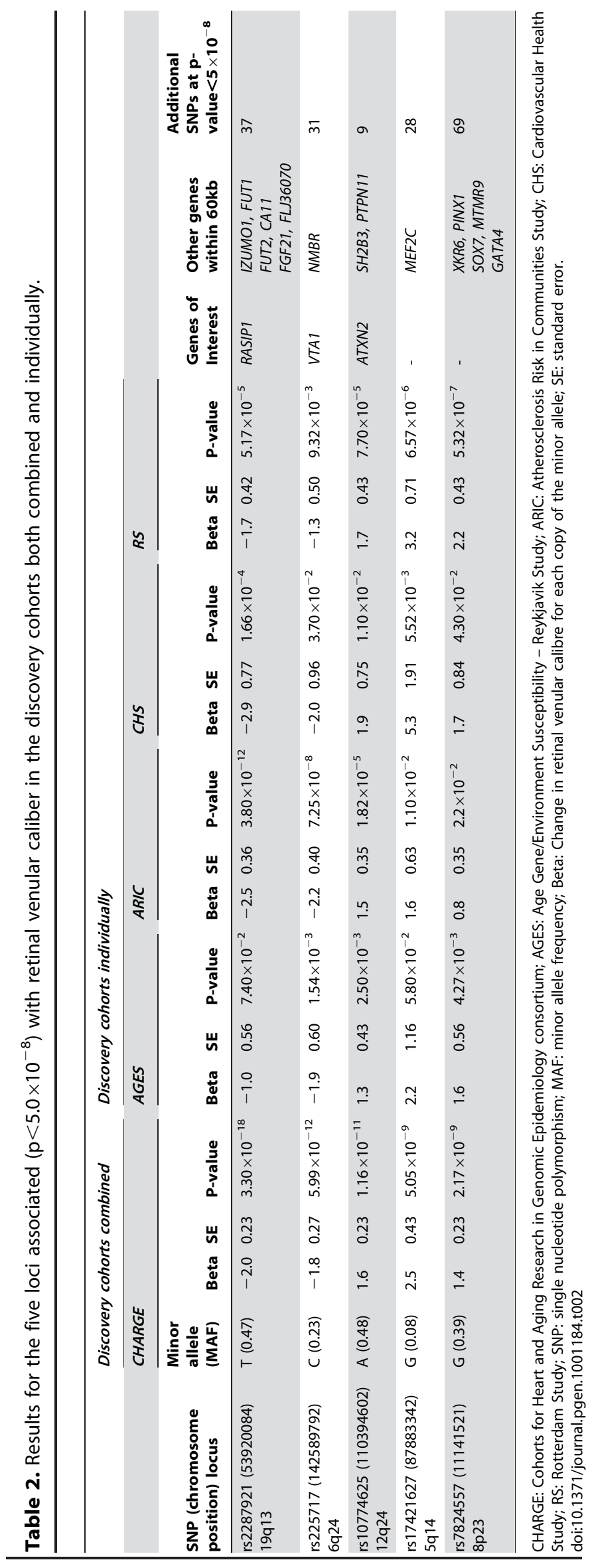




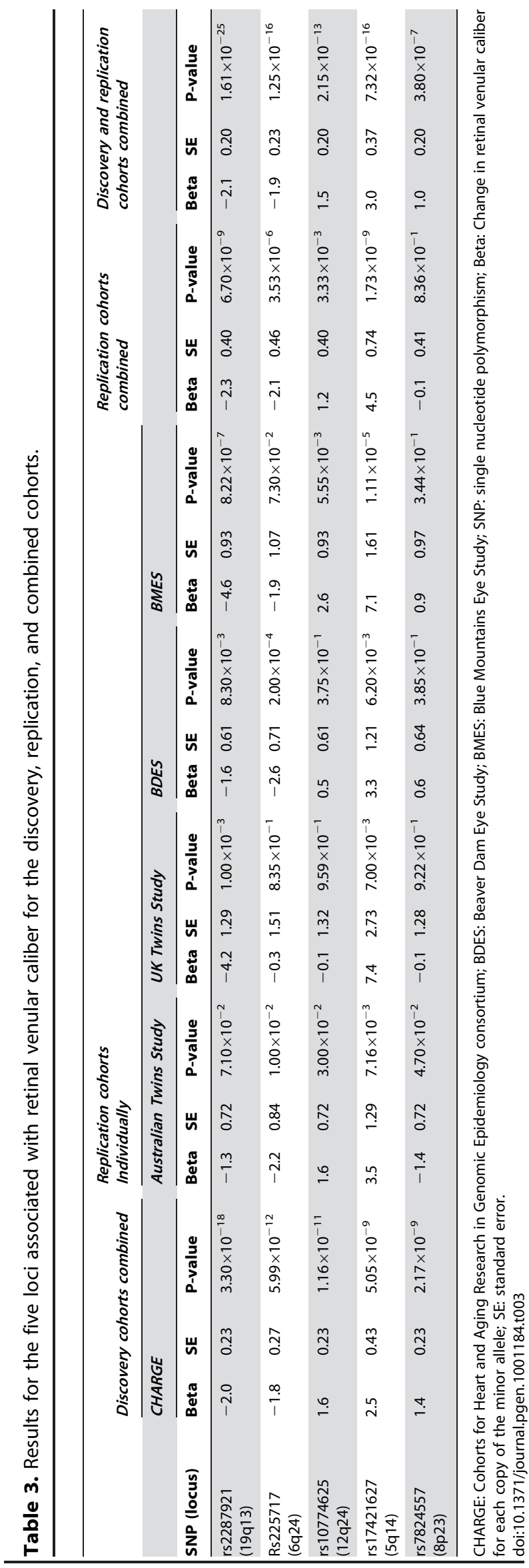

[33]. This is supported by clinical and epidemiological studies showing larger venular caliber to be associated with systemic biomarkers of inflammation, including C-reactive protein and interleukin-6, and with impaired fasting glucose metabolism, dyslipidemia, obesity and cigarette smoking [5,34].

The most significant SNP associated with retinal venular caliber was in the RASIP1 gene (rs2287921, $\left.\mathrm{p}=1.61 \times 10^{-25}\right)$ on chromosome 19q13. RASIP1 belongs to the family of $R A S$ molecules, which have recently been implicated in animal models to be involved in vascular development, endothelial cell migration, capillary tube assembly, blood vessel homeostasis and vascular permeability [35]. Specifically, RASIP1 is expressed in the endothelium of the developing blood vessels and is essential for proper endothelial cell angiogenic assembly and migration [35].

On chromosome 6q24, the top SNPs were located in or adjacent to VTA1 and $\mathcal{N} M B R$ genes. VTA1 encodes a protein involved in trafficking of the multivesicular body, an endosomal compartment involved in sorting membrane proteins for degradation in lysosomes [36]. Neuromedin $\mathrm{B}(\mathcal{N M B})$ is a peptide that acts by binding to a specific receptor protein $(\mathcal{N M B R})$ and is involved in a number of physiological processes including immune defense, thyroid, adrenocortical function and cognition. $\mathcal{N M B}$ is also aberrantly expressed by a variety of cancers and is involved in tumor cell proliferation [37].

The signals for association on chromosome $12 \mathrm{q} 24$ were spread across a large $1 \mathrm{Mb} \mathrm{LD}$ block, including genes such as $S H 2 B 3$, $A T X N 2$ and PTPN11. The most significant SNP was located in $A T X \mathcal{N} 2$. Defects in the $A T X \mathcal{N} 2$ are the cause of spinocerebellar ataxia type 2 (SCA 2), which belongs to the autosomal cerebellar ataxias characterized by cerebellar ataxia, optic atrophy, ophthalmoplegia and dementia. SCA 2 is caused by extension of a CAG repeat in the coding region of this gene. Another gene in this region is $S H 2 B 3$, which is expressed by vascular endothelial cells and regulates growth factor and cytokine receptor-mediated pathways implicated in lymphoid, myeloid and platelet homeostasis [38]. Our study showed that the most significant SNP in the $S H 2 B 3$ region was $\mathrm{rs} 3184504\left(\mathrm{p}=4.88 \times 10^{-11}\right)$. Interestingly, this variant is associated with type 1 diabetes mellitus, a disease in which the risk of developing complications was found to be associated with wider retinal venular caliber [38]. Recent GWAS studies have shown that several SNPs at the locus 12q24 (e.g. rs 11065987 in ATXN2 and rs 11066301 in PTPN11) are associated with platelet count, hemoglobin concentration, hematocrit, and blood pressure [39-41]. Furthermore, replication in independent case-control series including 9,479 cases and 10,527 controls have shown odds ratios of 1.14 (95\% CI: $1.10-1.20 ; \mathrm{p}=2.52 \times 10^{-9}$ ) and $1.15\left(95 \%\right.$ CI: $\left.1.10-1.20 ; \mathrm{p}=7.05 \times 10^{-11}\right)$ per minor allele copy for the association of these two SNPs with coronary artery disease [39]. The corresponding allelic odds ratios for myocardial infarction were 1.17 (95\% CI: $\left.1.11-1.22 ; \mathrm{p}=3.43 \times 10^{-10}\right)$ and 1.18 (95\% CI: $\left.1.12-1.23 ; \mathrm{p}=2.42 \times 10^{-12}\right)$ [39]. In our discovery cohort, apart from rs 10774625 we found nine additional SNPs in the region that were genome-wide significant, including both rs 11065987 and rs11066301 (1.5 increase in venular caliber per minor allele for both) that have also been shown to be associated with coronary heart disease and myocardial infarction. Finally, in the present study the association results from WTCCC and Global BPgen confirmed locus 12q24 to be a risk locus for both coronary artery disease and hypertension. Specifically, we found a strong overlap between the association signals of retinal venular caliber and coronay artery disease.

The most significant SNPs at the $5 q 14$ locus were located in an intergenic region. The closest gene in this region is $M E F 2 C$, which is located about $200 \mathrm{~kb}$ downstream. Myocyte enhancer factor 2 


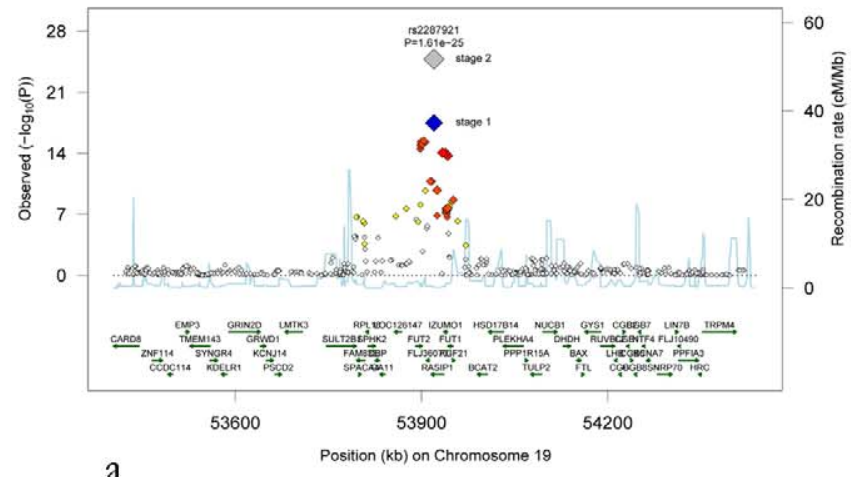

a

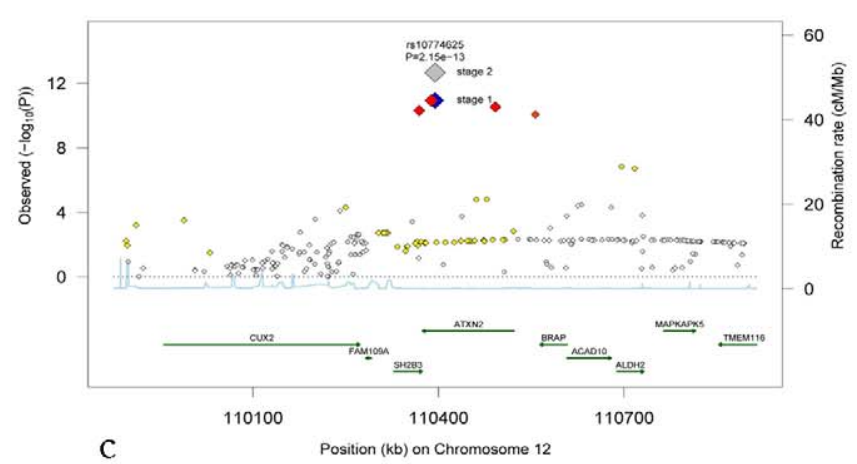

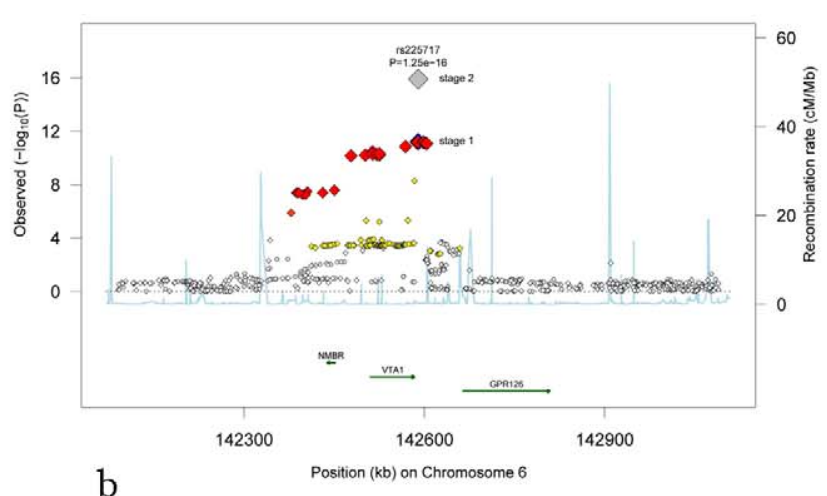

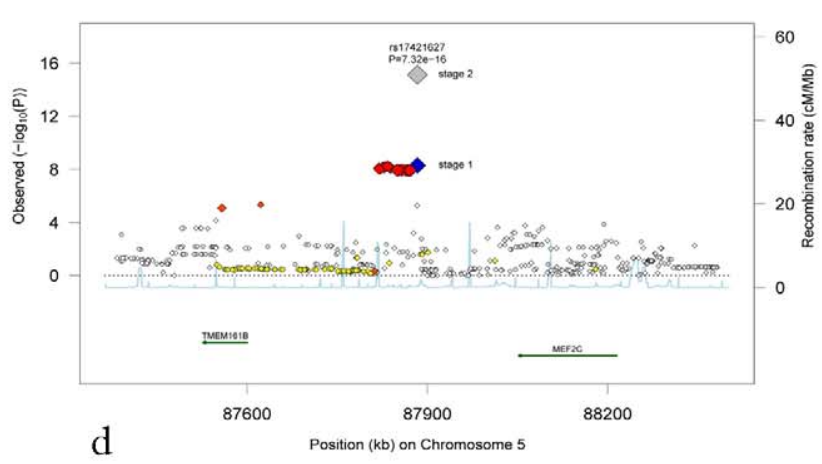

Figure 2. Regional association plots for the four novel loci. (a) Chromosome 19q13, (b) chromosome 6q24, (c) chromosome 12q24, and (d) chromosome 5q14. The blue diamonds show stage $1 \mathrm{p}$-values (discovery phase) for the top SNP at each locus, whereas the grey diamonds show the p-values following stage 2 meta-analysis including the replication cohorts for that top SNP. P-values from stage 1 for additional SNPs at each locus are colour-coded according to their linkage disequilibrium with the top SNP as follows: $r^{2}<0.2$ white, $0.2<r^{2}<0.5$ yellow, $0.5<r^{2}<$ orange-red, $r^{2}>0.8$ red. doi:10.1371/journal.pgen.1001184.g002

(MEF2) family proteins are key transcription factors, consisting of four members $M E F 2 A, M E F 2 B, M E F 2 C$ and $M E F 2 D$, controlling gene expression in myocytes, lymphocytes, and neurons. $M E F 2$ also plays an important role in cardiogenesis, epithelial cell survival and maintenance of blood vessel integrity. Knockout of $M E F 2 C$ gene in mice is embryologically lethal due to failure in cardiac development [42].
We did not find any loci that reached genome-wide significance for retinal arteriolar caliber. It is possible that genetic factors play a smaller role in arteriolar caliber, which is strongly associated with increasing age and blood pressure [5-8]. It is also possible that multiple genetic loci determine retinal arteriolar caliber and each locus exerts only a very weak association that is not detectable using our current study sample size. Thus, in order to examine

Table 4. The association between the four novel loci and cardiovascular diseases.

\begin{tabular}{|c|c|c|c|c|c|c|}
\hline & $\begin{array}{l}\text { CHARGE } \\
\text { (CRVE) }\end{array}$ & $\begin{array}{l}\text { WTCCC } \\
(C A D)\end{array}$ & $\begin{array}{l}\text { HVH } \\
\text { (stroke) }\end{array}$ & $\begin{array}{l}H V H \\
(M I)\end{array}$ & $\begin{array}{l}\text { Global BPgen } \\
\text { (HTN) }\end{array}$ & $\begin{array}{l}\text { DIAGRAM+ } \\
\text { (DM) }\end{array}$ \\
\hline $\begin{array}{l}\text { 12q24 } \\
\text { (rs10774625) } \\
\text { M.A.: A }\end{array}$ & $\begin{array}{l}\text { Beta: } 1.6 \\
\text { (SE } 0.23 \text { ) } \\
P=1.16 \times 10^{-11}\end{array}$ & $\begin{array}{l}\text { OR: } 1.13 \\
(1.03 ; 1.24) \\
P=0.008\end{array}$ & $\begin{array}{l}\text { OR: } 1.03 \\
(0.89 ; 1.20) \\
P=0.66\end{array}$ & $\begin{array}{l}\text { OR: } 1.05 \\
(0.94 ; 1.18) \\
P=0.39\end{array}$ & $\begin{array}{l}\text { OR: } 1.06 \\
(1.01 ; 1.12) \\
P=0.019\end{array}$ & $\begin{array}{l}\text { OR: } 1.02 \\
(0.98 ; 1.06) \\
P=0.36\end{array}$ \\
\hline $\begin{array}{l}\text { 19q13 (rs2287921) } \\
\text { M.A.: T }\end{array}$ & $\begin{array}{l}\text { Beta: }-2.0 \\
\text { (SE } 0.23 \text { ) } \\
P=3.30 \times 10^{-18}\end{array}$ & $\begin{array}{l}\text { OR: } 0.95 \\
(0.87 ; 1.05) \\
P=0.303\end{array}$ & $\begin{array}{l}\text { OR: } 0.90 \\
(0.77 ; 1.06) \\
P=0.20\end{array}$ & $\begin{array}{l}\text { OR: } 0.91 \\
(0.81 ; 1.03) \\
P=0.13\end{array}$ & $\begin{array}{l}\text { OR: } 1.01 \\
(0.96 ; 1.07) \\
P=0.67\end{array}$ & $\begin{array}{l}\text { OR: } 1.01 \\
(0.97 ; 1.05) \\
P=0.72\end{array}$ \\
\hline $\begin{array}{l}\text { 6q24 } \\
\text { (rs225717) } \\
\text { M.A.: C }\end{array}$ & $\begin{array}{l}\text { Beta: }-1.8 \\
\text { (SE } 0.27) \\
P=5.99 \times 10^{-12}\end{array}$ & $\begin{array}{l}\text { OR: } 0.98 \\
(0.89 ; 1.08) \\
P=0.65\end{array}$ & $\begin{array}{l}\text { OR: } 1.11 \\
(0.93 ; 1.32) \\
P=0.24\end{array}$ & $\begin{array}{l}\text { OR: } 1.12 \\
(0.98 ; 1.27) \\
P=0.11\end{array}$ & $\begin{array}{l}\text { OR: } 0.98 \\
(0.93 ; 1.04) \\
P=0.55\end{array}$ & $\begin{array}{l}\text { OR: } 0.98 \\
(0.93 ; 1.02) \\
P=0.33\end{array}$ \\
\hline $\begin{array}{l}\text { 5q14 } \\
\text { (rs17421627) } \\
\text { M.A.: G }\end{array}$ & $\begin{array}{l}\text { Beta: } 2.5 \\
\text { (SE } 0.43 \text { ) } \\
P=5.05 \times 10^{-9}\end{array}$ & $\begin{array}{l}\text { OR: } 1.02 \\
(0.88 ; 1.18) \\
P=0.81\end{array}$ & $\begin{array}{l}\text { OR: } 1.15 \\
(0.83 ; 1.59) \\
P=0.39\end{array}$ & $\begin{array}{l}\text { OR: } 1.02 \\
(0.79 ; 1.31) \\
P=0.89\end{array}$ & $\begin{array}{l}\text { OR: } 1.07 \\
(0.98 ; 1.17) \\
P=0.14\end{array}$ & $\begin{array}{l}\text { OR: } 0.98 \\
(0.91 ; 1.05) \\
P=0.60\end{array}$ \\
\hline
\end{tabular}

CHARGE: Cohort for Heart and Aging Research in Genomic Epidemiology Consortium CRVE: central retinal venular equivalent (CRVE), SE: standard error; WTCCC: Wellcome Trust Case Control Consortium; CAD: coronary artery disease; HVH: Heart and Vascular Health Study; MI: myocardial infarction; Global BPgen: Global Blood Pressure Genetics Consortium; HTN: hypertension; DIAGRAM+: Diabetes Genetics Replication and Meta-analysist; DM: diabetes mellitus; M.A.: Minor allele within CHARGE; OR: odds ratio (with corresponding $95 \%$ confidence interval) per copy of the minor allele.

doi:10.1371/journal.pgen.1001184.t004 


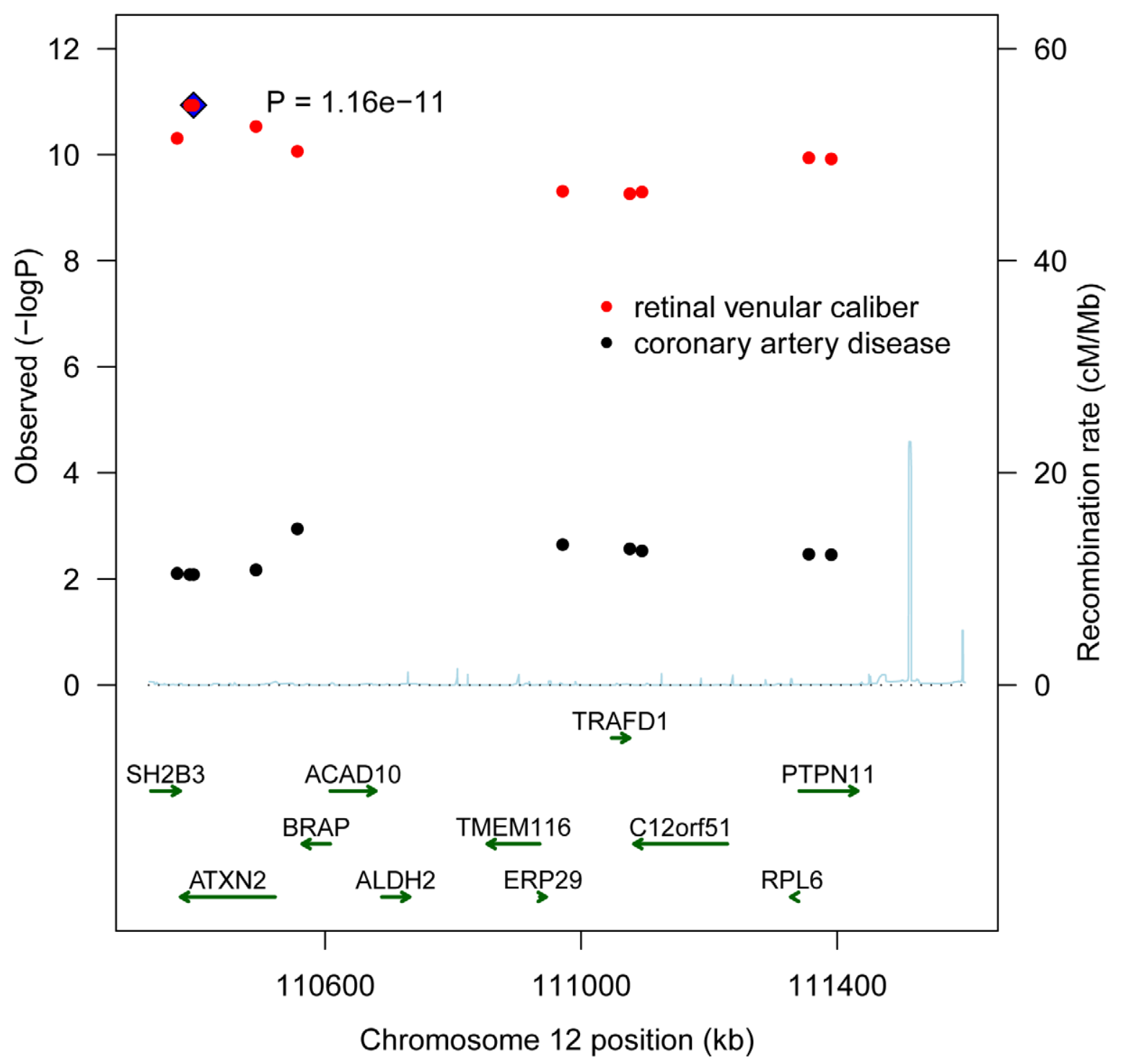

Figure 3. A combined regional association plot showing p-values from CHARGE for the 10 SNPs on $12 q 24$ for retinal venular caliber and from WTCCC for coronary artery disease.

doi:10.1371/journal.pgen.1001184.g003

genetic associations with retinal arteriolar caliber more fully, we are currently in the process of building collaborations with several other studies to increase the sample size of the discovery cohort.

While we have identified four loci associated with retinal venular caliber, the identified SNPs may not represent the causal variants but could be in high linkage disequilibrium $(\mathrm{LD})$ with the causal variants, which remain to be discovered. Further fine mapping of this genomic region will be required to facilitate expression and translational studies. Our study suggests that the effect of common genetic variants on retinal vascular caliber is small, and explain only a small proportion of the heritability of these traits [43]. It remains possible that low frequency variants might be important, but GWAS provides poor coverage of rare variants. With the study populations of predominantly Caucasian descent and stringent checks for latent population substructure, the associations are unlikely to be due to population stratification.

To conclude, our population-based GWAS demonstrate four novel loci on chromosomes 19q13 (within the RASIP1 locus), 6q24 (adjacent to the VTA1 and NMBR loci), 12q24 (in the region of the SH2B3, ATXN2 and PTPN11 loci) and 5q14 (adjacent to the MEF2C locus) associated with retinal venular caliber, an endophenotype of the microcirculation associated with clinical cardiovascular disease. Furthermore, locus 12q24 was also associated with coronary heart disease and hypertension. While further studies are needed to determine the causal genetic variants that underlie the heritability of this endophenotype, our findings will help focus research on novel genes and pathways involving the microvasculature and its role in the pathogenesis and development of cardiovascular disease.

\section{Materials and Methods}

\section{Ethics statement}

Each cohort secured approval from their respective institutional review boards, and all participants provided written informed consent in accordance with the Declaration of Helsinki.

\section{Consortium organization}

The CHARGE consortium included large prospective community-based cohort studies that have genome-wide marker data and extensive data on multiple phenotypes [21]. All participating 
studies approved guidelines for collaboration, and a working group arrived at a consensus on phenotype harmonization, covariate selection and analytic plans for within-study analyses and metaanalyses of results.

\section{Setting}

Details of cohort selection, risk factor assessment and retinal vascular caliber measurements in the four studies have been described in Text S1, section 1 [11,22-25]. The AGES is a prospective study with subject recruitment from 2002-2006 of 5,764 surviving members, aged 66 years and older, of the established Reykjavik Study, a cohort of 19,381 participants assembled in 1967 to study cardiovascular disease and its risk factors among those born between 1907 and 1935 [22]. The ARIC study enrolled 15,792 men and women (including 11,478 nonHispanic whites) from four U.S. communities to investigate the etiology and sequelae of atherosclerosis and cardiovascular risk factors [23]. Participants were between age 45 and 64 years at their baseline examination in 1987-1989. The CHS enrolled 5,888 adults 65 years and older from four field centers to study coronary artery disease and stroke. The baseline examination took place either in 1989-90 or 1992-93 [24]. The Rotterdam Study enrolled 7,983 inhabitants from a district of Rotterdam aged 55 years and older to study cardiovascular, neurological, ophthalmic and endocrine diseases. The baseline examination was in 1990-93 [25].

\section{Study population}

The AGES and Rotterdam cohorts consisted predominantly of Caucasian whites. Only non-Hispanic white participants were included from the ARIC and CHS. Retinal photographs were obtained from participants at the third examination in ARIC and the tenth in CHS. Participants were excluded if their photographs could not be graded (due to cataract, corneal opacities or poor focus) or if genotyping data were unavailable (Table 1).

\section{Retinal vascular caliber measurements}

Retinal vascular caliber was measured using standardized protocols and software that were developed initially at the University of Wisconsin and used in the ARIC study and the CHS, and following slight modifications, also in the Rotterdam and AGES studies (Text S1, section 2) [4,5,9,11,13]. In brief, participants underwent retinal photography and optic disccentered images were used to measure vascular caliber. Pharmacological mydriasis was used in the AGES and Rotterdam studies. For ARIC, CHS and Rotterdam the photographs of one eye were digitized using a high-resolution scanner and for the AGES study, photographs of both eyes were captured digitally. All digital retinal images were analyzed with a semi-automated retinal vessel measurement system and the calibers of all retinal arterioles and venules were measured in an area between half and one discdiameter from the optic disc margin. The Parr-HubbardKnudtson formulae were used to compute summary measures for retinal arteriolar and venular calibers in micrometers $(\mu \mathrm{m})$ and referred to as the "central retinal arteriolar and venular equivalents" [44]. Quality control (QC) measures for intergrader and intragrader intraclass correlation coefficients for retinal vascular calibers for each of the cohorts ranged from $0.76-0.99$ in AGES, 0.69-0.89 in ARIC, 0.67-0.91 in CHS to 0.67-0.95 in the Rotterdam Study $[4,5,9,13]$.

\section{Genotyping}

The consortium was formed after the individual studies had finalized their GWAS platform selection. The four studies included used different platforms: the Affymetrix GeneChip SNP Array 6.0 for the ARIC study, Illumina HumanCNV370-Duo for the AGES study and the CHS and the Illumina Infinium HumanHap550-chip v3.0 for the Rotterdam Study. All studies used their genotype data to impute to the 2.2 million nonmonomorphic, autosomal, SNPs identified in HapMap (CEU population). Extensive QC analyses were performed in each cohort (Text S1, sections 3 and 4) [21].

\section{Statistical analyses within discovery cohorts}

Based on an a priori analysis plan, each study fitted an additive genetic model with a 1-degree of freedom trend test relating the retinal arteriolar or venular caliber to genotype dosage (0-2 copies of the minor allele) for each SNP, adjusting for age and sex. For the CHS and ARIC studies, the analyses were additionally adjusted for study site. We used linear regression models to calculate regression coefficients (beta) and their standard errors (SE) using the ProbABEL program (http://mga.bionet.nsc.ru/ 〜yurii/ABEL/) in AGES, ARIC and Rotterdam study and the R software in CHS (http://www.r-project.org). Genomic control correction was applied in each study prior to the meta-analysis. To implement genomic control, the $\lambda_{\mathrm{gc}}$ value was used to correct the

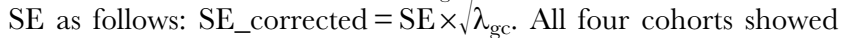
low dispersion with inflation factors in the range of 1.030-1.071.

\section{Meta-analysis}

We conducted a meta-analysis of the beta estimates obtained from the linear regression models from the four cohorts using an inverse-variance weighting using the $\mathrm{R}$ software (MetABEL) (Text S1, section 5) [45]. Strand information was available from all cohorts, facilitating the meta-analysis. After QC, filtering, and imputation within each study, we restricted our meta-analysis to the 2,194,468 autosomal SNPs that were common to all cohorts. We decided a priori on a genome-wide significance threshold of $\mathrm{p}<5.0 \times 10^{-8}$ which corresponds to a $\mathrm{p}$-value of 0.05 with Bonferroni correction for one million independent tests. For 2.2 million tests, it corresponds to an expectation of only 0.11 false positives, regardless of test-dependence [46]. Use of this threshold is also supported by LD patterns observed in deep sequencing work within European populations [47].

\section{Replication analyses}

The genome-wide significant SNPs for each locus from the discovery phase were examined in four replication cohorts. The four replication sample sets included 1,709 participants from the Australian Twins Study, 1,132 from the UK Twins Study, 2,501 from the BDES and 1,310 from the BMES. Retinal vascular caliber measurements used the same methodology and formulas as in the CHARGE cohorts. Details of this and the procedures for genotyping are described in the Text $\mathrm{S} 1$, sections 1 and 2 . In brief, in the Australian Twins Study, genotyping was performed on the Illumina Human Hap610W Quad array. In the UK Twins Study, $56 \%$ of the participants were genotyped using the Illumina $317 \mathrm{k}$ HumanHap duo array, whereas the remaining 44\% using the Illumina HumanHap610Quad array. In the BDES, SNPs were genotyped using TaqMan SNP genotyping assays (Applied Biosystems, CA). Finally, in the BMES genotyping was performed using the Illumina $610 \mathrm{~K}$ array.

\section{Analyses with cardiovascular diseases}

In order to examine the association between SNPs that were successfully replicated in the current study and cardiovascular diseases, we obtained association statistics for each of these SNPs 
from several GWA studies. We obtained these data from the WTCGC on 2000 cases with coronary artery disease and 3000 controls [3], from HVH Study on 501 cases with stroke [28], 1,172 cases with myocardial infarction and 1,314 controls [29], from Global BPgen on 8,871 cases with hypertension and 9,027 controls [30], and from DIAGRAM+ on 8,130 cases with diabetes mellitus and 38,987 controls [31]. Details of each these studies have been described in the Text $\mathrm{S} 1$, section 6 .

\section{Supporting Information}

Figure S1 Quantile-quantile (QQ)-plot showing the minus logtransformed observed versus the expected p-values after metaanalysis for (A) retinal venular and (B) arteriolar caliber.

Found at: doi:10.1371/journal.pgen.1001184.s001 (0.26 MB TIF)

Table S1 The association between the top SNPs per genomewide significant locus and retinal vascular caliber additionally adjusted for diabetes mellitus and hypertension.

Found at: doi:10.1371/journal.pgen.1001184.s002 (0.05 MB DOC)

Text S1 Sample selection, retinal vascular caliber measurements, genotyping quality control filters and imputation, screening for latent population substructure, meta-analysis techniques, analyses with cardiovascular diseases, reference list.

Found at: doi:10.1371/journal.pgen.1001184.s003 (0.09 MB DOC)

\section{Acknowledgments}

This study makes use of data generated by the Wellcome Trust CaseControl Consortium. A full list of the investigators who contributed to the generation of the data is available from www.wtccc.org.uk. In addition, we would also like to acknowledge Laura Scott and Goncalo Abecasis from the University of Michigan who assisted with the imputation of HAPMAP Single Nucleotide Polymorphisms for the WTCGC dataset.

We would also like to acknowledge the contributions of the Diabetes Genetics Replication and Meta-analysis+(DIAGRAM+) Consortium, which looked up the associations with type 2 diabetes mellitus for the SNPs associated with retinal venular caliber.

\section{Members of the Global Blood Pressure Genetics (BPgen)}

\section{Consortium}

Christopher Newton-Cheh ${ }^{1,2,3}$, Toby Johnson ${ }^{4,5,6}$, Vesela Gateva ${ }^{7}$, Martin D Tobin ${ }^{8}$, Murielle Bochud ${ }^{5}$, Lachlan Coin ${ }^{9}$, Samer S Najjar ${ }^{10}$, Jing Hua Zhao ${ }^{11,12}$, Simon C Heath ${ }^{13}$, Susana Eyheramendy ${ }^{14,15}$, Konstantinos Papadakis ${ }^{16}$, Benjamin F Voight ${ }^{1,3}$, Laura J Scott ${ }^{7}$, Feng Zhang $^{17}$, Martin Farrall ${ }^{18,19}$, Toshiko Tanaka ${ }^{20,21}$, Chris Wallace ${ }^{22,23}$, John C Chambers ${ }^{9}$, Kay-Tee Khaw ${ }^{12,24}$, Peter Nilsson ${ }^{25}$, Pim van der $\mathrm{Harst}^{26}$, Silvia Polidoro ${ }^{27}$, Diederick E Grobbee ${ }^{28}$, N Charlotte OnlandMoret $^{28,29}$, Michiel L Bots ${ }^{28}$, Louise V Wain ${ }^{8}$, Katherine S Elliott ${ }^{19}$, Alexander Teumer ${ }^{30}$, Jian'an Luan ${ }^{11}$, Gavin Lucas ${ }^{31}$, Johanna Kuusisto ${ }^{32}$, Paul R Burton ${ }^{8}$, David Hadley ${ }^{16}$, Wendy L McArdle ${ }^{33}$, Wellcome Trust Case Control Consortium ${ }^{34}$, Morris Brown ${ }^{35}$, Anna Dominiczak ${ }^{36}$, Stephen J Newhouse ${ }^{22}$, Nilesh J Samani ${ }^{37}$, John Webster ${ }^{38}$, Eleftheria Zeggini $^{19,39}$, Jacques S Beckmann ${ }^{4,40}$, Sven Bergmann ${ }^{4,6}$, Noha Lim $^{41}$, Kijoung Song ${ }^{41}$, Peter Vollenweider ${ }^{42}$, Gerard Waeber ${ }^{42}$, Dawn M' Waterworth $^{41}$, Xin Yuan ${ }^{41}$, Leif Groop ${ }^{43,44}$, Marju Orho-Melander ${ }^{25}$, Alessandra Allione ${ }^{27}$, Alessandra Di Gregorio ${ }^{27,45}$, Simonetta Guarrera ${ }^{27}$, Salvatore Panico ${ }^{46}$, Fulvio Ricceri ${ }^{27}$, Valeria Romanazzi ${ }^{27,45}$, Carlotta Sacerdote $^{47}$, Paolo Vineis ${ }^{9,27}$, Inês Barroso ${ }^{12,39}$, Manjinder $S$ Sandhu ${ }^{11,12,24}$, Robert N Luben ${ }^{12,24}$, Gabriel J. Crawford ${ }^{3}$, Pekka Jousilahti $^{48}$, Markus Perola ${ }^{48,49}$, Michael Boehnke ${ }^{7}$, Lori L Bonnycastle ${ }^{50}$, Francis S Collins ${ }^{50}$, Anne U Jackson ${ }^{7}$, Karen L Mohlke ${ }^{51}$, Heather M Stringham ${ }^{7}$, Timo T Valle ${ }^{52}$, Cristen J Willer ${ }^{7}$, Richard N Bergman ${ }^{53}$, Mario A Morken ${ }^{50}$, Angela Döring ${ }^{15}$, Christian Gieger ${ }^{15}$, Thomas Illig ${ }^{15}$, Thomas Meitinger ${ }^{54,55}$, Elin Org ${ }^{56}$, Arne Pfeufer ${ }^{54}$, H Erich Wichmann $^{15,57}$, Sekar Kathiresan ${ }^{1,2,3}$, Jaume Marrugat ${ }^{31}$, Christopher J O'Donnell ${ }^{58,59}$, Stephen M Schwartz ${ }^{60,61}$, David S Siscovick ${ }^{60,61}$, Isaac Subirana $^{31,62}$, Nelson B Freimer ${ }^{63}$, Anna-Liisa Hartikainen ${ }^{64}$, Mark I
McCarthy $^{19,65,66}$, Paul F O'Reilly ${ }^{9}$, Leena Peltonen ${ }^{39,49}$, Anneli Pouta ${ }^{64,67}$, Paul E de Jong ${ }^{68}$, Harold Snieder ${ }^{69}$, Wiek H van Gilst ${ }^{26}$, Robert Clarke ${ }^{70}$, Anuj Goel ${ }^{18,19}$, Anders Hamsten ${ }^{71}$, John F Peden ${ }^{18,19}$, Udo Seedorf ${ }^{72}$, Ann-Christine Syvänen ${ }^{73}$, Giovanni Tognoni ${ }^{74}$, Edward G Lakatta ${ }^{10}$, Serena Sanna ${ }^{75}$, Paul Scheet ${ }^{76}$, David Schlessinger ${ }^{77}$, Angelo Scuteri ${ }^{78}$, Marcus Dörr ${ }^{79}$, Florian Ernst ${ }^{30}$, Stephan B Felix ${ }^{79}$, Georg Homuth ${ }^{30}$, Roberto Lorbeer ${ }^{80}$, Thorsten Reffelmann ${ }^{79}$, Rainer Rettig ${ }^{81}$, Uwe Völker $^{30}$, Pilar Galan ${ }^{82}$, Ivo G Gut ${ }^{13}$, Serge Hercberg ${ }^{82}$, G Mark Lathrop $^{13}$, Diana Zeleneka ${ }^{13}$, Panos Deloukas ${ }^{12,39}$, Nicole Soranzo ${ }^{17,39}$, Frances M Williams ${ }^{17}$, Guangju Zhai ${ }^{17}$, Veikko Salomaa ${ }^{48}$, Markku Laakso $^{32}$, Roberto Elosua ${ }^{31,62}$, Nita G Forouhi ${ }^{11}$, Henry Völzke ${ }^{80}$, Cuno S Uiterwaal $^{28}$, Yvonne T van der Schouw ${ }^{28}$, Mattijs E Numans ${ }^{28}$, Giuseppe Matullo $^{27,45}$, Gerjan Navis ${ }^{68}$, Göran Berglund ${ }^{25}$, Sheila A Bingham ${ }^{12,83}$, Jaspal S Kooner ${ }^{84}$, John M Connell ${ }^{36}$, Stefania Bandinelli ${ }^{85}$, Luigi Ferrucci $^{21}$, Hugh Watkins ${ }^{18,19}$, Tim D Spector ${ }^{17}$, Jaakko Tuomilehto $^{52,86,87}$, David Altshuler ${ }^{1,3,88,89}$, David P Strachan ${ }^{16}$, Maris Laan ${ }^{56}$, Pierre Meneton ${ }^{90}$, Nicholas J Wareham ${ }^{11,12}$, Manuela Uda ${ }^{75}$, Marjo-Riitta Jarvelin $^{9,67,91}$, Vincent Mooser ${ }^{41}$, Olle Melander ${ }^{25}$, Ruth JF Loos ${ }^{11,12}$, Paul

Elliott $^{9}$, Gonçalo R Abecasis ${ }^{92}$, Mark Caulfield ${ }^{22}$, Patricia B Munroe ${ }^{22}$

1. Center for Human Genetic Research, Massachusetts General Hospital, 185 Cambridge Street, Boston, MA 02114, USA

2. Cardiovascular Research Center, Massachusetts General Hospital, Boston, Massachusetts 02114, USA

3. Program in Medical and Population Genetics, Broad Institute of Harvard and Massachusetts Institute of Technology, Cambridge, Massachusetts, 02142, USA

4. Department of Medical Genetics, University of Lausanne, 1005 Lausanne, Switzerland

5. University Institute for Social and Preventative Medicine, Centre Hospitalier Universitaire Vaudois (CHUV) and University of Lausanne, 1005 Lausanne, Switzerland

6. Swiss Institute of Bioinformatics, Switzerland

7. Department of Biostatistics and Center for Statistical Genetics, University of Michigan, Ann Arbor, MI 48109, USA

8. Departments of Health Sciences \& Genetics, Adrian Building, University of Leicester, University Road, Leicester LE1 7RH

9. Department of Epidemiology and Public Health, Imperial College London, St Mary's Campus, Norfolk Place, London W2 1PG, UK

10. Laboratory of Cardiovascular Science, Intramural Research Program, National Institute on Aging, National Institutes of Health, Baltimore, Maryland, USA 21224

11. MRC Epidemiology Unit, Institute of Metabolic Science, Addenbrooke's Hospital, Cambridge CB2 0QQ UK

12. Cambridge - Genetics of Energy Metabolism (GEM) Consortium, Cambridge, UK

13. Centre National de Génotypage, 2 rue Gaston Crémieux, CP 5721, 91057 Evry Cedex, France

14. Pontificia Universidad Catolica de Chile, Vicuña Mackenna 4860, Facultad de Matematicas, Casilla 306, Santiago 22, Chile, 7820436

15. Institute of Epidemiology, Helmholtz Zentrum München, German Research Centre for Environmental Health, 85764 Neuherberg, Germany 16. Division of Community Health Sciences, St George's, University of London, London SW17 0RE, UK

17. Department of Twin Research \& Genetic Epidemiology, King's College London, London SE1 7EH

18. Department of Cardiovascular Medicine, University of Oxford

19. The Wellcome Trust Centre for Human Genetics, Roosevelt Drive, Oxford, OX3 7BN, UK

20. Medstar Research Institute, 3001 S. Hanover Street, Baltimore, MD 21250, USA

21. Clinical Research Branch, National Institute on Aging, Baltimore, MD, 21250 USA

22. Clinical Pharmacology and The Genome Centre, William Harvey Research Institute, Barts and The London School of Medicine and Dentistry, Queen Mary University of London, London EC1M 6BQ

23. JDRF/WT Diabetes and Inflammation Laboratory, Cambridge Institute for Medical Research University of Cambridge, Wellcome Trust/ MRC Building, Addenbrooke's Hospital Cambridge, CB2 OXY

24. Department of Public Health and Primary Care, Institute of Public Health, University of Cambridge, Cambridge CB2 2SR, UK

25. Department of Clinical Sciences, Lund University, Malmö University Hospital, SE-20502 Malmö, Sweden 
26. Department of Cardiology University Medical Center Groningen, University of Groningen, Hanzeplein 1, 9700 RB Groningen, The Netherlands

27. ISI Foundation (Institute for Scientific Interchange), Villa Gualino, Torino, 10133, Italy

28. Julius Center for Health Sciences and Primary Care, University Medical Center Utrecht, STR 6.131, PO Box 85500, 3508 GA Utrecht, The Netherlands

29. Complex Genetics Section, Department of Medical Genetics - DBG,

University Medical Center Utrecht, STR 2.2112, PO Box 85500, 3508 GA Utrecht, The Netherlands.

30. Interfaculty Institute for Genetics and Functional Genomics, ErnstMoritz-Arndt-University Greifswald, 17487 Greifswald, Germany

31. Cardiovascular Epidemiology and Genetics, Institut Municipal d'Investigació Mèdica, Barcelona, Spain

32. Department of Medicine University of Kuopio 70210 Kuopio, Finland

33. ALSPAC Laboratory, Department of Social Medicine, University of Bristol, BS8 2BN, UK

34. A full list of authors is provided in the supplementary methods online.

35. Clinical Pharmacology Unit, University of Cambridge, Addenbrookes Hospital, Cambridge, UK CB2 2QQ

36. BHF Glasgow Cardiovascular Research Centre, University of Glasgow, Glasgow, UK G12 8TA

37. Department of Cardiovascular Science, University of Leicester, Glenfield Hospital, Groby Road, Leicester, LE3 9QP, UK

38. Aberdeen Royal Infirmary, Aberdeen, UK

39. Wellcome Trust Sanger Institute, Wellcome Trust Genome Campus,

Hinxton, Cambridge CB10 1SA, UK

40. Service of Medical Genetics, Centre Hospitalier Universitaire Vaudois (GHUV), Lausanne, 1011, Switzerland

41. Genetics Division, GlaxoSmithKline, King of Prussia, PA 19406, USA

42. Department of Internal Medicine, Centre Hospitalier Universitaire Vaudois (CHUV) 1011 Lausanne, Switzerland

43. Department of Clinical Sciences, Diabetes and Endocrinology

Research Unit, University Hospital, Malmö

44. Lund University, Malmö S-205 02, Sweden

45. Department of Genetics, Biology and Biochemistry, University of

Torino, Torino, 10126, Italy

46. Department of Clinical and Experimental Medicine, Federico II University, Naples, 80100, Italy

47. Unit of Cancer Epidemiology, University of Turin and Centre for Cancer Epidemiology and Prevention (CPO Piemonte), Turin, 10126, Italy

48. National Institute for Welfare and Health P.O. Box 30, FI-00271 Helsinki, Finland

49. Institute for Molecular Medicine Finland FIMM, University of Helsinki and National Public Health Institute

50. Genome Technology Branch, National Human Genome Research Institute, Bethesda, MD 20892, USA

51. Department of Genetics, University of North Carolina, Chapel Hill, NC 27599, USA

52. Diabetes Unit, Department of Epidemiology and Health Promotion,

National Public Health Institute, 00300 Helsinki, Finland

53. Physiology and Biophysics USC School of Medicine 1333 San Pablo Street, MMR 626 Los Angeles, California 90033

54. Institute of Human Genetics, Helmholtz Zentrum München, German Research Centre for Environmental Health, 85764 Neuherberg, Germany

55. Institute of Human Genetics, Technische Universität München, 81675 Munich, Germany

56. Institute of Molecular and Cell Biology, University of Tartu, 51010 Tartu, Estonia

57. Ludwig Maximilians University, IBE, Chair of Epidemiology, Munich

58. Cardiovascular Research Center and Cardiology Division, Massachusetts General Hospital, Boston, Massachusetts 02114, USA

59. Framingham Heart Study and National, Heart, Lung, and Blood Institute, Framingham, Massachusetts 01702, USA
60. Cardiovascular Health Research Unit, Departments of Medicine and Epidemiology, University of Washington, Seattle, Washington, 98101 USA

61. Department of Epidemiology, University of Washington, Seattle, Washington, 98195 USA

62. CIBER Epidemiología y Salud Pública, Barcelona, Spain

63. Center for Neurobehavioral Genetics, Gonda Center, Room 3506, 695 Charles E Young Drive South, Box 951761, UCLA, Los Angeles, CA 90095.

64. Department of Clinical Sciences/Obstetrics and Gynecology, P.O. Box 5000 Fin-90014, University of Oulu, Finland

65. Oxford Centre for Diabetes, Endocrinology and Metabolism, University of Oxford, Churchill Hospital, Old Road, Headington, Oxford OX3 7LJ, UK

66. Oxford NIHR Biomedical Research Centre, Churchill Hospital, Old Road, Headington, Oxford, UK OX3 7LJ

67. Department of Child and Adolescent Health, National Public Health Institute (KTL), Aapistie 1, P.O. Box 310, FIN-90101 Oulu, Finland

68. Division of Nephrology, Department of Medicine University Medical Center Groningen, University of Groningen, Hanzeplein 1, 9700 RB Groningen, The Netherlands

69. Unit of Genetic Epidemiology and Bioinformatics, Department of Epidemiology University Medical Center Groningen, University of Groningen, Hanzeplein 1, 9700 RB Groningen, The Netherlands

70. Clinical Trial Service Unit and Epidemiological Studies Unit (CTSU), University of Oxford, Richard Doll Building, Roosevelt Drive, Oxford, OX3 7LF, UK

71. Atherosclerosis Research Unit, Department of Medicine Solna, Karolinska Institutet, Karolinska University Hospital Solna, Building L8:03, S-17176 Stockholm, Sweden

72. Leibniz-Institut für Arterioskleroseforschung an der Universität Münster, Domagkstr. 3, D-48149, Münster, Germany

73. Molecular Medicine, Department of Medical Sciences, Uppsala University, SE-751 85 Uppsala, Sweden

74. Consorzio Mario Negri Sud, Via Nazionale, 66030 Santa Maria Imbaro (Chieti), Italy

75. Istituto di Neurogenetica e Neurofarmacologia, GNR, Monserrato, 09042 Cagliari, Italy

76. Department of Epidemiology, Univ. of Texas M. D. Anderson Cancer Center, Houston, TX 77030

77. Laboratory of Genetics, Intramural Research Program, National Institute on Aging, National Institutes of Health, Baltimore, Maryland, USA 21224

78. Unitá Operativa Geriatria, Istituto Nazionale Ricovero e Cura per Anziani (INRCA) IRCCS, Rome, Italy

79. Department of Internal Medicine B, Ernst-Moritz-Arndt-University Greifswald, 17487 Greifswald, Germany

80. Institute for Community Medicine, Ernst-Moritz-Arndt-University Greifswald, 17487 Greifswald, Germany

81. Institute of Physiology, Ernst-Moritz-Arndt-University Greifswald, 17487 Greifswald, Germany

82. U557 Institut National de la Santé et de la Recherche Médicale, U1125 Institut National de la Recherche Agronomique, Université Paris 13, 74 rue Marcel Cachin, 93017 Bobigny Cedex, France

83. MRG Dunn Human Nutrition Unit, Wellcome Trust/MRG Building, Cambridge CB2 0XY, U.K

84. National Heart and Lung Institute, Imperial College London SW7 $2 \mathrm{AZ}$

85. Geriatric Rehabilitation Unit, Azienda Sanitaria Firenze (ASF), 50125, Florence, Italy

86. Department of Public Health, University of Helsinki, 00014 Helsinki, Finland

87. South Ostrobothnia Central Hospital, 60220 Seinäjoki, Finland

88. Department of Medicine and Department of Genetics, Harvard Medical School, Boston, Massachusetts 02115, USA

89. Diabetes Unit, Massachusetts General Hospital, Boston, Massachusetts 02114 , USA

90. U872 Institut National de la Santé et de la Recherche Médicale, Faculté de Médecine Paris Descartes, 15 rue de l'Ecole de Médecine, 75270 Paris Cedex, France

91. Institute of Health Sciences and Biocenter Oulu, Aapistie 1, FIN90101, University of Oulu, Finland 
92. Center for Statistical Genetics, Department of Biostatistics, University of Michigan, Ann Arbor, Michigan 48109 USA

\section{Author Contributions}

Conceived and designed the experiments: RK BEKK MMBB NG PM AGU FR AH PTVMdJ CMvD BMP FJ GE TA LJL KDT SKI CJH JIR EB VG DSS JRV TYW. Analyzed the data: MKI SX RAJ MFC AWH

\section{References}

1. Camini PG, Crea F (2007) Coronary microvascular dysfunction. N Engl J Med 356: 830-840.

2. Watkins H, Farrall M (2006) Genetic susceptibility to coronary artery disease: from promise to progress. Nat Rev Genet 7: 163-173.

3. Wellcome Trust Case Control Consortium (2007) Genome-wide association study of 14,000 cases of seven common diseases and 3,000 shared controls. Nature 447: 661-678.

4. Hubbard LD, Brothers RJ, King WN, Clegg LX, Klein R, et al. (1999) Methods for evaluation of retinal microvascular abnormalities associated with hypertension/sclerosis in the Atherosclerosis Risk in Communities Study. Ophthalmology 106: 2269-2280.

5. Ikram MK, De Jong FJ, Vingerling JR, Witteman JC, Hofman A, et al. (2004) Are retinal arteriolar or venular diameters associated with markers for cardiovascular disorders? The Rotterdam Study. Invest Ophthalmol Vis Sci 45: 2129-2134.

6. Wong TY, Mitchell P (2004) Hypertensive retinopathy. N Engl J Med 351: 2310-2317.

7. Wong TY, Klein R, Sharrett AR, Duncan BB, Couper DJ, et al. (2004) Atherosclerosis Risk in Communities Study. Retinal arteriolar diameter and risk for hypertension. Ann Intern Med 140: 248-255.

8. Wong TY, Klein R, Sharrett AR, Schmidt MI, Pankow JS, et al. (2002) Retinal arteriolar narrowing and risk of diabetes mellitus in middle-aged persons. JAMA 287: 2528-2533.

9. Qiu C, Cotch MF, Sigurdsson S, Garcia M, Klein R, et al. (2008) Retinal and cerebral microvascular signs and diabetes: the age, gene/environment susceptibility-Reykjavik study. Diabetes 57: 1645-1650.

10. McGeeshan K, Liew G, Macaskill P, Irwig L, Klein R, et al. (2009) Prediction of incident stroke events based on retinal vessel caliber: a systematic review and individual-participant meta-analysis. Am J Epidemiol 170: 1323-1332.

11. McGeechan K, Liew G, Macaskill P, Irwig L, Klein R, et al. (2009) Metaanalysis: retinal vessel caliber and risk for coronary heart disease. Ann Intern Med 151: 404-413.

12. Ikram MK, De Jong FJ, Van Dijk EJ, Prins ND, Hofman A, et al. (2006) Retinal vessel diameters and cerebral small vessel disease: The Rotterdam Scan Study. Brain 129: 182-188.

13. Longstreth W, Jr., Larsen EK, Klein R, Wong TY, Sharrett AR, et al. (2007) Associations between findings on cranial magnetic resonance imaging and retinal photography in the elderly: the Cardiovascular Health Study. Am J Epidemiol 165: 78-84.

14. Jeganathan VS, Kawasaki R, Wang.JJ, Aung T, Mitchell P, et al. (2008) Retinal vascular caliber and age-related macular degeneration: the Singapore Malay Eye Study. Am J Ophthalmol 146: 954-959.

15. Nguyen TT, Wang JJ, Sharrett AR, Islam FM, Klein R, et al. (2008) Relationship of retinal vascular caliber with diabetes and retinopathy: the MultiEthnic Study of Atherosclerosis (MESA). Diabetes Care 31: 544-549.

16. Klein R, Klein BE, Moss SE, Wong TY (2007) Retinal vessel caliber and microvascular and macrovascular disease in type 2 diabetes: XXI: the Wisconsin Epidemiologic Study of Diabetic Retinopathy. Ophthalmology 114: 1884-1892.

17. Xing G, Klein BE, Klein R, Jun G, Lee KE, et al. (2006) Genome-wide linkage study of retinal vessel diameters in the Beaver Dam Eye Study. Hypertension 47: 797-802.

18. Wang JJ, Wong TY (2006) Genetic determinants of retinal vascular caliber: additional insights into hypertension pathogenesis. Hypertension 47: 644-645.

19. Liew G, Shankar A, Wang.JJ, Klein R, Bray MS, et al. (2007) Apolipoprotein E gene polymorphisms and retinal vascular signs: the atherosclerosis risk in communities (ARIC) study. Arch Ophthalmol 125: 813-818.

20. De Jong FJ, Ikram MK, Despriet DD, Uitterlinden AG, Hofman A, et al. (2007) Complement factor $\mathrm{h}$ polymorphism, inflammatory mediators, and retinal vessel diameters: the rotterdam study. Invest Ophthalmol Vis Sci 48: 3014-3018.

21. Psaty BM, O'Donnell CJ, Gudnason V, Lunetta KL, Folsom AR, et al. (2009) Cohorts for Heart and Aging Research in Genomic Epidemiology (CHARGE) Consortium: Design of prospective meta-analyses of genome-wide association studies from five cohorts. Circ Cardiovasc Genet 2: 73-80.

22. Harris TB, Launer LJ, Eiriksdottir G, Kjartansson O, Jonsson PV, et al. (2007) Age, Gene/Environment Susceptibility-Reykjavik Study: multidisciplinary applied phenomics. Am J Epidemiol 165: 1076-1087.

23. The Atherosclerosis Risk in Communities (ARIC) Study: design and objectives (1989) The ARIC investigators. Am J Epidemiol 129: 687-702.
MAIJJW GL FR GMvD LK CYC AVS NLG TL BM TBH XL QX TAS DAM SM NGM TLY JCB KLW SRH TA SF EGH EST TYW. Wrote the paper: MKI SX RAJ MFC AWH MAI JJW RK BEKK MMBB NC GL PM AGU AH PTVMdJ LK CYG AVS NLG TL BM BMP FJ GE TA TBH LJL KDT XL SKI QX TAS DAM SM NGM TLY CJH TA SF JA EGH RJS FMAI JIR AKM EB EST VG DSS JRV TYW.

24. Fried LP, Borhani NO, Enright P, Furberg CD, Gardin JM, et al. (1991) The Cardiovascular Health study: design and rationale. Ann Epidemiol 1: 263-276.

25. Hofman A, Breteler MM, van Duijn CM, Janssen HL, Krestin GP, et al. (2009) The Rotterdam Study: 2010 objectives and design update. Eur J Epidemiol 24: $553-572$.

26. Mackey DA, Mackinnon JR, Brown SA, Kearns LS, Ruddle JB, et al. (2009) Twins Eye Study in Tasmania (TEST): Rationale and Methodology to Recruit and Examine Twins. Twin Res Hum Genet 12: 441-454.

27. Hammond CJ, Snieder H, Spector TD, Gilbert CE (2000) Genetic and environmental factors in age-related nuclear cataracts in monozygotic and dizygotic twins. N Engl J Med 342: 1786-1790.

28. Psaty BM, Heckbert SR, Koepsell TD, Siscovick DS, Raghunathan TE, et al. (1995) The risk of myocardial infarction associated with antihypertensive drug therapies. JAMA 274: 620-625.

29. Klungel OH, Heckbert SR, Longstreth WT, Jr., Furberg CD, Kaplan RC, et al. (2001) Antihypertensive drug therapies and the risk of ischemic stroke. Arch Intern Med 161: 37-43.

30. Newton-Cheh C, Johnson T, Gateva V, Tobin MD, Bochud M, et al. (2009) Genome-wide association study identifies eight loci associated with blood pressure. Nat Genet 41: 666-676.

31. Voight BF, Scott LJ, Steinthorsdottir V, Morris AP, Dina C, et al. (2010) Twelve type 2 diabetes susceptibility loci identified through large-scale association analysis. Nat Genet 42: 579-589.

32. Tamai K, Matsubara A, Tomida K, Matsuda Y, Morita H, et al. (2002) Lipid hydroperoxide stimulates leukocyte-endothelium interaction in the retinal microcirculation. Exp Eye Res 75: 69-75.

33. Chester AH, Borland JA, Buttery LD, Mitchell JA, Cunningham DA, et al. (1998) Induction of nitric oxide synthase in human vascular smooth muscle: interactions between proinflammatory cytokines. Cardiovasc Res 38: 814-821.

34. Wong TY, Islam FM, Klein R, Klein BE, Cotch MF, et al. (2006) Retinal vascular caliber, cardiovascular risk factors and inflammation: the Multi-Ethnic Study of Atherosclerosis. Invest Ophthalmol Vis Sci 47: 2341-2350.

35. Xu K, Chong DC, Rankin SA, Zorn AM, Cleaver O (2009) RASIP1 is required for endothelial cell motility, angiogenesis and vessel formation. Dev Biol 329: 269-279.

36. Xiao J, Xia H, Zhou J, Azmi IF, Davies BA, et al. (2008) Structural Basis of Vta1 Function in the Multivesicular Body Sorting Pathway. Dev Cell 14: 37-49.

37. Matusiak D, Glover S, Nathaniel R, Matkowskyj K, Yang J, et al. (2005) Neuromedin $\mathrm{B}$ and its receptor are mitogens in both normal and malignant epithelial cells lining the colon. Am J Physiol Gastrointest Liver Physiol 288: 718-728.

38. Smyth DJ, Plagnol V, Walker NM, Cooper JD, Downes K, et al. (2008) Shared and distinct genetic variants in type 1 diabetes and celiac disease. N Engl J Med 359: $2767-2777$.

39. Soranzo N, Spector TD, Mangino M, Kühnel B, Rendon A, et al. (2009) A genome-wide meta-analysis identifies 22 loci associated with eight hematological parameters in the HaemGen consortium. Nat Genet 41: 1182-1190.

40. Ganesh SK, Zakai NA, Van Rooij FJ, Soranzo N, Smith AV, et al. (2009) Multiple loci influence erythrocyte phenotypes in the CHARGE consortium. Nat Genet 41: 1191-1198.

41. Levy D, Ehret GB, Rice K, Verwoert GC, Launer LJ, et al. (2009) Genomewide association study of blood pressure and hypertension. Nat Genet. in press.

42. Ma K, Chan JK, Zhu G, Wu Z (2005) Myocyte enhancer factor 2 acetylation by p300 enhances its DNA binding activity, transcriptional activity, and myogenic differentiation. Mol Cell Biol 25: 3575-3582.

43. Manolio TA, Collins FS, Cox NJ, Goldstein DB, Hindorff LA, et al. (2009) Finding the missing heritability of complex diseases. Nature 461: 747-753.

44. Knudtson MD, Lee KE, Hubbard LD, Wong TY, Klein R, et al. (2003) Revised formulas for summarizing retinal vessel diameters. Curr Eye Res 27: 143-149.

45. Schlesselman JJ (1997) Risk of endometrial cancer in relation to use of combined oral contra-ceptives: a practitioner's guide to meta-analysis. Human Reprod 12: 1851-1863.

46. Gordon A, Glazko G, Qiu X, Yakovlev A (2007) Control of the mean number of false discoveries, Bonferroni and stability of multiple testing. Ann Appl Statistics 1: 179-190.

47. Hoggart CJ, Clark TG, De Iorio M, Whittaker JC, Balding DJ (2008) Genomewide significance for dense SNP and resequencing data. Genet Epidemiol 32: $179-185$. 